\title{
Aprestos para pensar eso de una Filosofía Latinoamericana ${ }^{1}$
}

\section{Preparations to think that on a Latin American Philosophy Aprestos para pensar isso de uma Filosofia Latino-Americana} Martín Ríos López²

\section{1.}

Agradezco infinitamente la invitación a estar acá hoy con ustedes. Cuestión que en un caso como este se agradece doblemente. Estoy agradecido fundamentalmente porque entiendo que es una invitación a dialogar. Entonces al no ser esta una situación de aula, es, por tanto, una situación, digámoslo así, de pura gratuidad.

No dejo de sentirme agradecido también por un segundo motivo no lejano del anterior: porque el origen de esta charla es resultado de la invitación que me fue extendida por algunos de los estudiantes de esta escuela. Y los estudiantes son, en última instancia, quienes, a la larga o a la corta, finalmente terminan validando la labor docente y al docente.

Entonces, mi presencia acá, hoy, se debe exclusivamente a la responsabilidad de los estudiantes. Hago énfasis en ello porque, siendo así, me siento libre para decir algunas palabras, y si estas aburren, ya sabrán a quién culpar.

\footnotetext{
1 Una versión preliminar se presentó en el III Ciclo de Charlas, Organizadas por el Centro de Estudiantes de Filosofía de la Universidad Católica Silva Henríquez y la Revista Estudiantil Exterioridad, el 12 de marzo de 2015 en el Campus Lo Cañas de la misma universidad.

2 Profesor de Filosofía, Escuela de Trabajo Social, FACSO, Universidad de Chile y miembro del Centro de Estudios del Pensamiento Iberoamericano, CEPIB de la Universidad de Valparaíso.
} 
Luego de esto, lo primero que quería contar, casi como anécdota, era que, en rigor, esta charla, en un primer momento la había pensado con otro nombre. Se iba a llamar -ipreste atención y escúchelo bien!- En las sandalias de Sócrates. Los primeros pasos por tierras americanas. Ello porque la invitación a charlar sobre el pensamiento latinoamericano, me exponía -y me expone- a hablar sobre un algo de lo cual en modo alguno soy experto. Tierras nuevas para sandalias gastadas, podría ser la imagen más adecuada. Un título así tenía por objeto ser, a fin de cuentas, una cardinalidad de mí en la situación actual. Un desafío en toda regla.

Entonces, al haber aceptado el diálogo, fue que me convertí, creo, en una especie de Sócrates en tierras americanas. Ello fundamentalmente porque, vuelvo a insistir, no puedo declararme como un 'especialista' en pensamiento latinoamericano, al modo que los especialistas se definen a sí mismos.

Aunque el título original, ya sabemos, finalmente terminó por quedarse en una anécdota, valga tenerlo en consideración.

Ahora mismo, si lo pienso bien, y a pesar de haber cambiado el título, no por ello he dejado de sentirme como un Sócrates al menos por otros tres motivos.

Primero: porque al igual que Sócrates, ese que describe Platón en Fedro, me he visto invitado a hablar antes unos jueces (63b), unos jueces verdaderos, por cierto, en un espacio que se dan filósofos y amigos. $Y$ en tal caso, al igual que Sócrates, si bien puedo tener amigos, lo cierto es que nunca he tenido discípulos y tampoco aspiro a tenerlos.

Es en este espacio de gratuidad, en este espacio del diálogo, espacio que sólo los amigos pueden darse, que he aceptado hablar en torno a un tema del cual, insisto, para nada soy experto, y, al igual que Sócrates, tendría que afirma de principio a fin que 'sólo sé que nada sé'. No soy, como se suele decir en los pasillos de la academia, un especialista. He ahí, por cierto, un segundo punto en común. Pero como estamos entre amigos, podemos hablar como amigos, esto es, con la gratuita sinceridad de la ignorancia. Una ignorancia que 
a la postre nos permite, si no dar una respuesta, al menos inventarla. Cuestión que, sin duda, termina, al fin y al cabo, siendo más interesante.

La tercera y última situación por la cual, como ya he dicho antes, me siento un poco Sócrates es que, muy posiblemente, mi consabida ignorancia termine siendo una molestia. Probablemente en este diálogo, a sostener entre nosotros, tenga que ofrecer más preguntas que respuestas. Se recordará que, por el hecho de preguntar sin cesar, fue que Sócrates se ganó, como sabemos, el apelativo de 'El tábano de Atenas'. En mi caso, infinitamente más modesto, quizás me termine ganando el apelativo de 'El tábano de Lo Cañas'.

Pero más allá de bromas, lo cierto es que la actividad socrática basada en el diálogo esconde, como hemos de saber, un peligro. El diálogo es un modo de 'decir verdad'. Y al 'decir verdad' se juega uno la vida. La filosofía, muy por el contrario de lo que pueda llegar a suponer, es una actividad de riesgo, es una actividad donde se pone en peligro la vida misma. La filosofía, es, en más de algún sentido, un educar para la muerte. Pensar, poetizar, filosofar son oficios que llevan entrañados un peligro de muerte. La muerte tiene la facultad de adoptar muchos rostros más allá del meramente físico: unas veces adopta la forma del exilio, otras de la censura, en otras de la incomprensión, y hasta del aislamiento. Con todo, y como no sabemos hacer otra cosa, habrá que estar dispuestos a correr el riesgo, aun cuando posteriormente seamos acusados, condenados y asesinados.

Dicho esto, pongámonos, entonces, en camino. Con estas sandalias con hedor a Europa a caminar por estas tierras de América.

\section{2.}

Antes de todo, una cuestión que se hace importante tener en consideración. Una consideración que opera, en rigor, como una suerte de advertencia. Atiéndase entonces a la advertencia. Esta charla se titula "Aprestos para pensar eso de una Filosofía Latinoamericana". Debemos decir que en el presente título no hay sarcasmos de ningún 
tipo, ni menos aún una consideración despectiva hacia un tópico de la filosofía en clave americana.

Entiéndase desde ahora que en el 'eso' del título de la presente exposición, en tanto es un pronombre demostrativo, me juego, ni más ni menos que una mostración. Es decir, en el horizonte de todo diálogo venidero trato sólo de mostrar 'algo' más que 'de-mostrar' algo. En este diálogo lo que intentaré hacer es 'poner algo a la vista'. Para mostrar algo basta sólo un dedo. Por eso podemos convenir, de entrada, que siempre estamos a un dedo de distancia de convertirnos en filósofos. En mi opinión, de los cinco, dos son los privilegiados para la filosofía por su capacidad crítica. El primero, es el dedo índice. Ya recordarán el cuadro de La escuela de Atenas de Rafael, donde Platón y Aristóteles privilegian ese dedo por sobre los demás. El primero apunta hacia arriba, el otro hacia abajo. El segundo, es el dedo medio. Casi sin lugar a dudas el filósofo que encarna de manera más viva esta imagen es Diógenes de Sínope.

Si para el dedo índice lo esencial se halla en la capacidad de indicar, mostrar, hacer ver, entonces se puede decir que, de algún modo, encarna por antonomasia el acto de acusar. Porque: indico, para acusar; muestro, para acusar; hago ver, para acusar. Al acusar, a) pongo en entredicho, b) fracturo la normalidad de los eventos, c) pongo fuera de contexto, d) expongo lo inconfesable. Con el dedo medio, tenemos otro tanto. Es este, otro gesto indicativo. Una modulación que, bajo sus reglas, también quiere hacer ver o mostrar, pero sobre todo se alza para disentir, para romper con eso otro que tengo en frente, para despreciar, casi siempre, algún principio de autoridad que se nos quiere imponer como condición de heteronomía. En este marco axiológico de lo indicativo, como será de suponer -y de modo contrario a lo sostenido anteriormente-, nunca podrá existir pretensión filosófica alguna si se utiliza el dedo pulgar. En un dedo pulgar alzado al cielo, nunca, pero jamás nunca, podrá haber una 'filosofía jovial'.

En ese pronombre indicativo, como decía, me juego una mostración. Me juego en la idea de que es posible señalar, ya con uno u otro dedo, un intersticio, esto es, unos supuestos que, por lo general, circulan 
como moneda común y sobre los cuales se erigen, en la mayoría de los casos, los cimientos de un posible pensamiento latinoamericano. ¿Cuáles serían esos supuestos? Por un lado, que así como hay un pensamiento europeo, existe un pensamiento latinoamericano; y por otro, que entre uno y otro, Europa y América Latina, media un océano de distancia, fundamentalmente porque Europa, parece ser, desconoce a América Latina y sus singularidades, a raíz de que este imaginario que viene a ser Europa, ocupa, a razón de sí mismo, un lugar privilegiado a la hora de darse a la filosofía. Este ejercicio filosófico en clave continental, desplazaría a un segundo o tercer plano todas aquellas manifestaciones filosóficas de otras latitudes, generando, como será de notar, una dinámica geopolítica de centro-periferia.

Siendo más explícito aún, digo, como primera cuestión, que, al tratar estos temas, existe el supuesto de que el pensamiento, tanto "europeo" como "latinoamericano", tienen una manifestación unívoca. Asunto sobre el cual no estaría tan seguro. Por otro, que la relación que se establece entre un pensamiento europeo y otro latinoamericano es resultado de una tensión de gradación ontológica, si se quiere decir así, donde hay locaciones filosóficas de primer y segundo orden. Tensión que habría que ajustar a sus debidas formas, según me parece ver.

¿Qué da pie a pensar eso de la filosofía europea en clave monolítica? ¿Qué entiende un europeo, como Heidegger, por eso que es Europa?

Es importante decir esto porque, a golpe de los años, una y otra vez se nos ha sugerido, que, a partir del texto de Heidegger como el ¿Qué es la filosofía?, por ejemplo, se podrían rastrear los signos más indicativos de la supuesta constitución monolítica del pensamiento europeo así como de su locuaz privilegio para darse a la tarea de filosofar.

Mucho de lo supuesto, al menos, insisto, en cuanto a Heidegger se refiere en estos asuntos, se desprende a partir de la reflexión que se va hilvanando en torno a la noción de filosofía, la que, finalmente, decanta en la siguiente idea: "la afirmación 'es griega en su esencia' no dice otra cosa que Occidente y Europa, y sólo ellos, son en lo más profundo de su curso histórico originariamente filosóficos" (37). 
Esta última afirmación de Heidegger encierra muchísimas dificultades si no somos capaces de sostener una lectura atenta. Sería un error, por ejemplo, pretender explicar que, bajo la sugerente noción de "Filosofía europea Occidental", (contenida también en Qué es eso la filosofía) se entiende, per se, todo cometido filosófico que se desarrolla en el continente geográfico de "Europa". ¿Qué argumentos pueden sostener primeramente la idea que existe una relación análoga entre los conceptos de Europa Occidental con el de Europa así a secas? ¿Es acaso lo mismo decir filosofía europea occidental que decir filosofía europea? De momento me atrevo a sostener -como hipótesis preliminar- que no. Que no es lo mismo. Pero, insisto, sólo de momento. Que bajo estas sutilezas, así como en otras, se esconde el quid profundo del asunto. Primero, porque cuando Heidegger hace referencia al concepto de Occidente, podemos pensar que deja fuera -en la exterioridad de lo posible- a una Filosofía europea oriental. Esa externa orientalidad del pensamiento europeo, a la que se refiere Heidegger en concreto, pero de un modo cuasi silencioso y entre líneas, es, cuando menos, el "pensamiento marxista" en cualquiera de sus claves: ya bajo la línea ortodoxa o heterodoxas, da igual.

Entonces la posibilidad de la filosofía se forja, como será de notar, en Occidente, a decir de Heidegger, pero no en Oriente. Pero más aún, y como segundo asunto, cabe, bajo este registro de análisis, hacer la pregunta por lo siguiente. ¿Qué está entendiendo Heidegger por Occidente? Por un lado, y como hemos venido indicando, Occidente no sólo es aquello que, por oposición, no es Oriente, sino en concreto aquello que puede llegar a ser Occidente y Europa a la vez. De ahí la consabida tesis de Heidegger en torno a un Occidente no-nato. Por otro, y en relación con lo dicho, hay que afirmar que Europa no es, para el caso, un continente puramente geográfico. Antes que todo, es, un continente espiritual. Entonces así, y sólo así, sería posible sostener, finalmente, que es lo mismo la filosofía europea occidental que la filosofía europea. Originariamente, entonces, Occidente es Europa. En ello existe una suerte de tautología, pues al nombrar Europa se dice, esto es, se hacer referencia inmediata a Occidente. Europa y Occidente, por tanto, cruzarían sus destinos y serían, pues, dos modos de nombrar -al menos en Heidegger- una y la misma cosa. 
Sin embargo, y para dar un paso más, sería importante continuar pensando en torno a qué entiende Heidegger por esa noción bifronte de Europa-Occidente. Que es, por lo demás, y esto sería necesario no olvidar, el espacio donde se inscribe de modo cierto la posibilidad de una Filosofía. Hagámonos, pues, la siguiente pregunta: ¿piensa acaso Heidegger que España, Portugal, Bélgica, Italia, o incluso Francia o Inglaterra son parte de ese Occidente? Como hipótesis me atrevería a afirmar, de momento, nuevamente, que no. Occidente, esto es, Europa, esto es, el espacio privilegiado y exclusivo de la filosofía, habría que afirmar, es, para Heidegger, ni más ni menos que Deutschland. En este punto vuelvo a poner a la vista la misma cita de Heidegger que poco antes ya había ofrecido: "La afirmación "es griega en su esencia" no dice otra cosa que Occidente y Europa, y sólo ellos son en lo más profundo de su curso histórico originariamente filosóficos." Sumado a lo anterior, será de notar otro aspecto capital del asunto, de no menor cuantía y digno de seguir siendo pensado. Y es que para Heidegger, si bien la lengua filosófica tiene en la lengua griega su encarnación y su momento de irrupción originario, es, sin embargo, en la lengua alemana donde tiene su originaria continuidad y consumación plena. La lengua filosófica, por tanto, tiene un aliento nacional, particular y no meramente metafísico. La filosofía se piensa y se habla en lenguas de experiencia. La pregunta acá sería ¿es que toda lengua tendría la posibilidad de hablar filosóficamente? Para Heidegger, muy posiblemente, sería algo imposible. No toda lengua sería apta y adecuada para la filosofía. Sólo para dejar abiertas interrogantes, habría que decir que esta última idea hace una referencia explícita a La retórica de Aristóteles, -ya lo recordarán ustedes por sus estudios en filosofía antigua-, lugar donde se señala que hay lenguas dadoras de sentido y otras simplemente receptoras de sentido. De eso se podría deducir que las primeras serían, entonces, lenguas aptas para la filosofía; las otras no. De ahí el gesto casi compulsivo de citar en otra lengua, que poco tiene que ver, como pudiera decirse por ahí, que eso es un 'falso recurso pedagógico', o una 'traductología o etimología superficial'; es, por el contrario, en toda regla un problema filosófico que bien podría llegar a sintetizarse en las siguientes preguntas: ¿es el castellano una lengua dadora de sentido?, ¿es posible, por tanto, pensar en lengua 
castellana? O más aún ¿es posible pensar América Latina a través de una lengua, en rigor, no americana? Parte del problema es que, si bien no somos esa figura continental europea, tampoco somos pura experiencia de pueblos originarios. América es, y vale no olvidar, una construcción del imaginario europeo, o, como diría Edmundo O'Gorman, América es una invención.

Entonces, según creemos, habría que precisar un poco más el asunto y decir que es una invención del imaginario hegemónico europeo. Lo que viaja con Colón es, como dirá Antonio de Nebrija, en la primera Gramática de la lengua castellana de 1492: la lengua, la espada y la religión. Entonces, a lo sumo, somos pura hibridación y mestizaje, lo que exige pensar, ya no en idea de 'identidad' latinoamericana, sino por el contrario sería pertinente preguntar por la locación de una idea en torno a la 'diferencia' latinoamericana capaz de conjugar el inmenso mosaico de experiencias e historias convergentes y divergentes. Esto, entiéndase bien, no es una respuesta, sino el indicio primero de un problema que no resolveremos acá, pero que sí me parece pertinente poner a la vista. Pensamos esta América Latina bajo el signo de la herencia de una lengua castellana y colonizadora. Somos fundamentalmente experiencia de hibridación.

¿Es acaso posible, en razón de lo dicho, sostener, aún, que la filosofía europea se expresa en clave monolítica? Me parece que no. Que es insostenible dar cabida, todavía hoy, a la creencia de un pensamiento europeo o de una filosofía europea. Del mismo modo que me niego a creer que existe un pensamiento o una filosofía latinoamericana. Lo que existe es, ya en un caso, ya en el otro, una manifestación plural y viva del pensamiento y la filosofía. El desafío, así las cosas, se encuentra en explicar el por qué se acostumbra a reducir a una dimensión singular el pensamiento o la filosofía. Insisto, ya en clave europea o latinoamericana. En otras palabras, ¿qué dimensión política se oculta tras ese ferviente deseo de manifestación unívoco?

En la filosofía, al contrario de lo que se pretende hacernos creer -por parte de la academia-, existe una dimensión política. Porque la filosofía posee una incidencia en el corpus social. Por ello es que la filosofía es 
política. Con ello tenemos entonces que, siendo la filosofía política, es a la vez, también histórica. Si hablamos de una filosofía europea, o de una filosofía latinoamericana, es porque hay una historia que contar. Una historia que habla de vencidos y vencedores. O si se quiere decir de otro modo, todo aquello que se manifiesta como un "pensamiento europeo" o un "pensamiento latinoamericano", es la resultante victoriosa en una serie de continuas luchas. De ellas una determina facción, finalmente, ha terminado triunfadora. Y, en virtud de su triunfo, actúa con potestad hegemónica. Ello no significa que todo pensamiento europeo o latinoamericano se reduzca o se pueda ver reducido a la tradición triunfante. Hay una suerte de caricaturización reduccionista en quienes se esmeran en sostener que todo el pensamiento europeo es hegemónico. El hecho cierto es que no todo pensamiento europeo es hegemónico, ni todo pensamiento hegemónico europeo reduce la vital realidad histórica del pensamiento europeo, que es, al igual que el latinoamericano, plurívoco. Las reflexiones de Raúl FornetBetancourt, por ejemplo, parecen ir en esta misma dirección cuando sostiene, al pensar en la institucionalización de los estudios filosóficos en Latinoamérica, que "las facultades de filosofía en América Latina son el reflejo de la cultura hegemónica y apuntalan, con las metodologías que transmiten y los contenidos que enseñan, la hegemonía cada vez más monocultural (filosófica) dominante. ${ }^{13}$ El deseo de dominación global de determinadas estructuras europeas se inscribe, como hemos estado sosteniendo, sobre el poder constituyente de la hegemonía. La que se supone, hasta ahora, al servicio de una clase.

Acontece que tras cada victoria, el vencedor ha sido capaz, en la potestad de su triunfo, de promulgar una amnesia generalizada. Al menos como deseo, lo que pretende es provocar un olvido de lo vencido. El sistemático olvido del pensamiento no hegemónico, por parte del vencedor, opera como estrategia para desactivar los elementos subversivos

3 FORNET-BETANCOURT, Raúl. "¿Qué hacer con la enseñanza de la filosofía? o la necesidad de reaprender a enseñar filosofía". Revista Concordia, Tomo 37, 2004. en SANTOS HERCEG, José. Cartografía crítica. El quehacer profesional de la filosofía en Chile, Santiago de Chile: Ediciones La Cañada, 2015, p. 57. 
que puedan contener, ya como residuo o como ruina. En el olvido se normaliza, se reduce a prescindible, y, si no eso, cuando menos, se nos hace pasar por un pensamiento de talla menor; innecesario para su circulación, promoción o validación. Con ello, todo pensamiento no hegemónico es rebajado y degradado categorialmente; ridiculizado epistémicamente y desactivado políticamente. Tres dimensiones que terminan confinándole a un menosprecio.

Pero hemos de saber que todo proceso hegemónico es una estancia transitiva. Nunca se gana para siempre, sino para estar en constante alerta. Hay una doble lucha, por un lado externa, con aquellos distintos de mí, y otra interna, puesto que se lleva a cabo como resultado de su propia adecuación al nuevo estado de cosas. Cada proceso hegemónico encuentra resistencias internas. Todo pensamiento hegemónico tiene sus cismas y herejías. De ahí que en todo tiempo cada instante es suficiente para la redención.

Lo ciertamente significativo es que bajo la categoría de hegemonía, que afecta, como hemos visto, al decurso de la filosofía, ya en clave europea o latinoamericana, acontece una voluntad de poder, ya en su dimensión histórica, política, social, cultural y religiosa, con arreglo a intereses de clase y casta, que pretende, entre otras cosas, construir, esto es, legalizar, normar, sacralizar un determinado paradigma que permita la reproducción de él mismo conforme y en arreglo a los intereses que le son propios a una clase dominante y privilegiada.

A lo largo de la historia se han canonizado autores, clasificándoles como pensadores de primera línea, o como clásicos ineludibles a la hora de abordar temas o problemas específicos. Bajo esta práctica ocurre ineludiblemente que otros -problemas, autores, temas- quedan confinados a una situación subordinada -bastarda-, periférica. La validación de cuáles son y cuáles no son los problemas centrales son potestad inalienable del poder hegemónico que dicta qué cae dentro del registro posibilidad de comunicabilidad a través de los dispositivos dispuestos. Uno de esos dispositivos de prácticas de legitimación es la universidad, y los académicos que las habitan, en mucho, responden a las demandas propias de la institución y por ende del poder hegemónico al que se deben. A aquellos académicos deudores del poder 
hegemónico, un pensador como Antonio Gramsci les clasifica bajo el acápite de intelectuales orgánicos. Y lo significativo del intelectual orgánico es que son personas que con su oficio, esencialmente intelectual, contribuyen a legitimar una estructura hegemónica de poder, sin importar que sea o no justa para la mayor parte de la sociedad. Buena parte de la filosofía académica es, haciendo una extensión del concepto, una suerte de Filosofía orgánica, que hace extensiva la labor del intelectual orgánico al interior del trabajo de la institución universidad. Es importante tener presente esta categoría 'europea' de hegemonía porque es a partir de ella que muchos pensadores latinoamericanos, queriendo construir un corpus de interpretación propio, fue que esbozaron el concepto de colonización. Este punto sólo lo dejo insinuado, pero sería del todo importante volver a él en otro momento.

Tenemos entonces, a pesar de todo lo que se diga, más en común con lo europeo de lo que se supone. Las desigualdades que aquejan a los pueblos están esbozadas más allá de un margen puramente continental. El saqueo de América en nada benefició a la gente común de Europa. El hambre, la peste, la desgracia, la explotación son problemas que han afectado por igual a los pueblos de aquí y de allá. Si hubo algún beneficiado por la explotación, ya en una u otra orilla, siempre han sido los mismos, una clase, una casta. En este horizonte, quizá, cobre sentido la afirmación de John Locke, cuando en el Segundo Tratado del Gobierno Civil afirma que "Al principio, todo el mundo era América".

Por tanto (y como reflexión final) habría que consignar que, según mi opinión, lo verdaderamente considerable a tener en cuenta como debilidad en la formación en un FODA sería, no el carácter demasiado eurocéntrico de la currícula universitaria, sino, haciendo la debida precisión, en el carácter demasiado hegemónico a la que tiende la misma. Y eso, como será de notar, es otro asunto. ¿Por qué se encuentran ausentes pensadores tan gravitantes como Pascal, Diderot o Spinoza? O lo que vendría a ser lo mismo, ¿por qué se insiste tan recurrentemente en una y otra asignatura en la metafísica de Aristóteles y se deja casi en el olvido a la Retórica o la Física? Y por extensión, otro tanto. 
¿Alguien se ha preguntado por cuánto sabemos de la singularidad del pensamiento filosófico en Chile? (y que no es lo mismo decir: filosofía chilena o filosofía desde Chile. Un asunto que da para una tesis o, al menos, para otra ponencia). ¿Se trata todo esto en alguna cátedra? ¿Por qué hay un olvido de la filosofía en Chile? Un olvido que juega a favor, en los casos en que es posible, a una filosofía latinoamericana. ¿Cómo se puede pensar la relación entre una filosofía latinoamericana con una filosofía en Chile? Nos podemos preguntar incluso: ¿Por qué hay una presencia mayor de $\mathrm{H}$. Giannini -ya por las tesis realizadas en su nombre, los artículos que le refieren o la cantidad de obras que a él respectan en algunos programas de formación filosófica-, presencia que contrasta con una ausencia, y por qué no decirlo, hasta con un desprecio casi absoluto de Juan Rivano, Enrique Molina Garmendia o Patricio Marchant? ¿Alguien de los estudiantes presentes hoy acá les conoce? La historia, así como la filosofía, se construye a partir de deseos y ausencias. $Y$ las presencias, quiérase o no, responden a compromisos que no se pueden negar, ya con unos, ya con otros.

Hay que pensar Latinoamérica. Ciertamente es esta una cuestión que urge. Es una tarea que, hoy por hoy, es indispensable, pero para alcanzar ese objetivo hay que pensarla, esto es, hacerse cargo de la cuestión desde la singularidad más propia y más relevante, desde ese espacio olvidado y denostado hasta la saciedad, donde efectivamente sería posible construir el acontecer de ese universal situado, concepto que proviene, como sabemos, de manos de la tradición hegemónica europea de herencia hegeliana, y que mucho gustan de conjurar algunos filósofos a la hora de pensar Latinoamérica. Esa posibilidad, la de pensar Latinoamérica, sin embargo, a mi parecer, se encuentra de modo ineludible ligada, en tanto en cuanto es ésta una tarea, al plano de una inmanencia más singular, al trabajo, la búsqueda y el encuentro de una Filosofía en Chile. 